Name : Valerie F. N Lapod

NRP : 130419014

\title{
How SROI affects social value
}

Social Return on Investment (SROI) is a form of assessment that providing answers to these questions of assessment such as; intent, utilization, and design, via mechanisms such as Social Impact Bonds (SIBs) and Pay for Success (PFS) (Yates \& Marra, 2017) Additionally, SROI is a method that has social impact and allows not for profit organizations to prove that the value of their work have wider range (Watson, Evans, Karvonen, \& Whitley, 2016) by assigning monetary to social returns using financial proxies and implementing traditional cost benefit analysis, are ways to determine SROI ratio to social outcomes (SO). Roberts Enterprise Development Fund (REDF) was the first organization that develop this method in mid-1990s (Watson, Evans, Karvonen, \& Whitley, 2016) There are pros and cons against SROI approach, people believe it is neither possible nor desirable to reduce SO and became monetary measures. On the other hand, SROI supporters believed that its ability to draw attention to intangible result by presenting them in generally recognized unit of value encourages broader discussion of what is important. (Watson, Evans, Karvonen, \& Whitley, 2016) Moreover, SROI analysis has strength to improve nonprofit organizations performance and social enterprise (Cordes, 2017)

According to (Watson, Evans, Karvonen, \& Whitley, 2016) there are six stages of SROI approach:

\section{1) Establishing scope and identifying key stakeholders}

This stage has purposes to analyzing and collecting data through interview or semi-interview and the data will be use later in the SROI process.

2) Mapping outcomes

A set of focus group that discuss about their experiences, needs and preferences, how they use the space, impact of the design and suggested improvements.

3) Evidencing outcomes and giving them a value

Survey the outcomes from previous stage. In order to produce quantitative measurements the data must be collected electronically and analyzed for descriptive statistics to obtain frequencies and averages.

4) Establishing impact

Interrogations the previous survey to find its impact. The impact is determined from survey data and the percentages removed from the financial proxies. 


\section{5) Calculating the SROI}

SROI ratio measures by calculating the costs, social returns, and payback period.

6) Reporting, using and embedding.

An end-user SROI report was created for one of the occupation organizations interested in learning from the findings and currently considering implementing SROI to more of its centres.

According to (Pratono, Suyanto, Marciano, \& Zurbrügg, 2017) there are several advantages and disadvantages of SROI. First the advantages are 1) The communities members like to take part in a development program in this case waste management and helped the communities' strengthen the relationship between child-parents and the neighborhood; 2) Increasing healthy lifestyle; 3) The community can reduce vegetables cost. 4) Gained income from recycling non-organic products and compost product; 5) Awarded for their best performance for Green and Clean Kampong. On the other hand, the disadvantages is a limitations in this research, so future research is needed to obtains resources from various perspective and conduct longitudinal survey of various cases to explore various levels of impact. And due to lack of literature that could provide financial proxy it may leads to inaccurate information of the costs.

\section{Bibliography}

Cordes, J. J. (2017). Using cost-benefit analysis and social return on investment to evaluate the impact of social enterprise: Promises, implementation, and limitations. Evaluation and Program Planning, 98-104.

Pratono, A. H., Suyanto, Marciano, D., \& Zurbrügg, C. (2017). SOCIAL RETURN ON INVESTMENT FOR COMMUNITY-BASED ENTERPRISE IN SURABAYA CITY. The Hong Kong Journal of Social Work, 93114.

Watson, K. J., Evans, J., Karvonen, A., \& Whitley, T. (2016). Capturing the social value of buildings: The promise of Social Return on Investment (SROI). Building and Environment, 289-301.

Yates, B. T., \& Marra, M. (2017). Introduction: Social Return On Investment (SROI). Evaluation and Program Planning, 95-97. 